\title{
Profesionales de la salud y emblematización urbana en la ciudad de rango medio
}

\author{
Bárbara Galarza
}

Facso-Unicen-Conicet, Olavarría, Argentina barbaragalarza@gmail.com

\begin{abstract}
Resumen: El objetivo del presente trabajo es verificar la hipótesis de la incidencia de la escala metropolitana como un obstáculo epistemológico dentro de los imaginarios urbanos de la salud de la ciudad media, tomando como fuente etnográfica las representaciones de los profesionales de la salud y su distinción emblemática local en situaciones de migración, especialización y valorización. Para esto, se describe y analiza el proceso social de construcción de prestigio de los profesionales a escala local. Se identifican así las trayectorias de migración de los actores y su entramado urbano como elementos constitutivos de este prestigio que es construido con imágenes nativas de próceres y dioses. Esta elaboración, propia de la urbanización de rango medio, resulta una paradoja significativa cuya producción de sentido tiene por efecto convertir a los profesionales de la salud de "laburantes", de la metrópolis intranquila, en "próceres" de la ciudad de referencia emblematizada como "la ciudad del trabajo". La investigación demuestra que la construcción social del prestigio profesional que se articula a la producción de emblemas urbanos locales contribuye a la producción y reproducción de la segmentación social que promueve el proceso de urbanización capitalista en las ciudades de rango medio del centro bonaerense. En este proceso, los emblemas de la ciudad media vista en contraste con la metrópolis funcionan como integradores obstaculizadores de la identidad de trabajador del profesional.

Palabras clave: Metrópolis; ciudad media; profesionales de la salud; emblematización urbana; especialización.
\end{abstract}

Cuadernos de Antropología

Julio-Diciembre 2016, 26(2), 27-50

DOI: $10.15517 /$ cat.v26i2.26488

Recibido: 31-08-2016 / Aceptado: 23-09-2016 / Publicado: 13/12/2016

Revista del Laboratorio de Etnología María Eugenia Bozzoli Vargas

Escuela de Antropología, Universidad de Costa Rica

http://revistas.ucr.ac.cr/index.php/antropologia

ISSN 2215-356X 


\begin{abstract}
Health professionals and urban emblematization in the middle range city
Abstract: The aim of this study is to verify the hypothesis of incidence of the metropolitan scale as an epistemological obstacle in the study of health urban imaginaries in the middle range city. For this, we take into account the representations of health professionals and their local emblematic distinction in situations of migration, specialization and valorization as an ethnographic source. We then describe and analyze the social process through which professionals build up prestige locally. Actor's migration paths are a key constituent element of this prestige which urban fabric is built upon native images of heroes and gods. This fabric, typical of the middle range urbanization, serves as a paradox that has the effect of converting health professionals from "laburantes" in the metropolis into "founding fathers" and "heroes" in the city of reference emblematized as "the city of work ". Research provides evidence showing how the social construction of professional prestige -linked to the production of local urban emblems- contributes to the production and reproduction of social segmentation that is promoted by the process of capitalist development in the middle range cities of the center of the province of Buenos Aires. In this process, the emblems of these cities, contrasting those of the metropolis, function as integrators that hinder the identity of the professional worker. Keywords: Metropolis; middle range city; health professionals; urban emblematization; specialization.
\end{abstract}

\title{
Introducción
}

Este artículo se inscribe dentro de una investigación en curso en la que se abordan antropológicamente los consumos colectivos urbanos a partir de las prácticas y representaciones vinculadas a servicios públicos sanitarios. Esta se desarrolla dentro del proyecto de investigación Antropología de ciudades medias del centro bonaerense: sistema urbano, imaginarios sociales y tramas de poder (Conicet, PIP 2015-2017), bajo la dirección de Ariel Gravano. Aplicando el método etnográfico, en este proyecto buscamos conocer cómo se viven las ciudades, además de cómo se vive en ellas, dando relevancia teórica a la dimensión significacional del fenómeno urbano. Así, intentamos comprender el proceso socio-cultural a través del cual el sistema urbano estructura tramas de poder locales (políticas, empresariales, profesionales) que se cristalizan en los imaginarios sociales urbanos de la región. Nuestro foco está puesto en estudiar, de modo integral, la cuestión urbana, articulando las representaciones simbólicas e identitarias que componen los imaginarios locales en los procesos histórico-estructurales que conforman el fenómeno de la reproducción urbana.

En este artículo se busca, por tanto, contribuir a la reconstrucción e interpretación de imaginarios sociales vinculados a los profesionales de la salud y a sus pacientes; de modo tal, de describir etnográficamente algunos de los componentes de la dinámica cultural sobre la que funcionan los servicios públicos de salud en las ciudades de rango medio del centro bonaerense de la República Argentina ${ }^{1}$.

1 En Argentina, el rango medio suele definirse por indicadores de tipo estándar, como el número de habitantes (entre 50000 y 500 000) (Boggi y Galván, 2016), pero desde un enfoque antropológico adquiere mayor importancia la dimensión simbólicoidentitaria (Silva y Boggi, 2016).

Cuadernos de Antropología 2016, 26(2), 27-50 / ISNN 2215-356X

http://revistas.ucr.ac.cr/index.php/antropologia 
El estudio de las ciudades medias, en general, y de la región centro bonaerense, en particular, resulta un área de gran vacancia en la antropología argentina. El modo en que nos proponemos contribuir a la producción de conocimiento sobre este objeto se apoya en dos aproximaciones epistemológicas centrales: el enfoque dialéctico y el método etnográfico. El primero nos insta a construir nuestro objeto de estudio sobre la base de la constitución histórica y estructural de la urbanización de rango medio. El segundo nos lleva a abordar la producción y reproducción urbana a partir de la producción cultural o praxis de los propios actores. Tendremos en cuenta no solo las representaciones explícitas que contribuyen a valorizar a los profesionales determinando su prestigio local, sino también las prácticas institucionalizadas de manera informal que contribuyen a reforzar o controlar ese prestigio. Trataremos de demostrar, pues, que el proceso de construcción del prestigio local del profesional de la salud en la ciudad media se da en estrecha vinculación con su capacidad de emblematizar localmente un valor de cambio que se produce urbanamente; esto quiere decir, a través de procesos sociales y simbólicos que incluyen el contraste comparativo con ciudades de rango metropolitano para ser efectivos. En este sentido, el análisis antropológico que se desarrolla a partir de las vivencias de los actores en torno a la migración y la especialización profesional constituye el contenido cultural de un fenómeno que consideramos articulador del desarrollo capitalista ${ }^{2}$ de la región en las primeras dos décadas del siglo XXI.

El trabajo se organiza de la siguiente manera. En primer lugar, se describe el perfil de la ciudad de Olavarría y el método utilizado en la investigación. En segundo lugar, se desarrolla una reflexión en torno al metropolismo como obstáculo epistemológico al que debe enfrentarse el analista nativo de la ciudad media. En tercer lugar, se intenta mostrar etnográficamente cómo la especialización de los profesionales de la salud en la ciudad media es un proceso social constituido no únicamente por la adquisición específica de conocimientos, sino también por dos tipos de migraciones o trayectorias urbanas. En cuarto lugar, se elabora una reflexión a partir de estos resultados de investigación que relaciona la construcción social del prestigio profesional a la producción de emblemas urbanos locales.

\section{Metodología}

El centro de la provincia de Buenos Aires, de la región pampeana en la que se sitúa el estudio, es en la actualidad uno de los territorios de explotación agrícola y minera y desarrollo industrial más importante de la Argentina. La ciudad de Olavarría posee una población aproximada de 100000 habitantes y es cabeza del partido homónimo (Figura 1). Su perfil industrial se vincula estrechamente a la industria del cemento. La instalación de fábricas cementeras en localidades aledañas desde la primera mitad del siglo XX y la explotación minera de recursos que proveen a esas industrias han sido las principales fuentes de empleo para la población local. El mercado de trabajo se constituye en términos generales de empleados de estas

2 Cabe aclarar que afirmamos esto teniendo en mente una definición antropológica y holística de este modo de producción que no coincide con reduccionismos economicistas. 


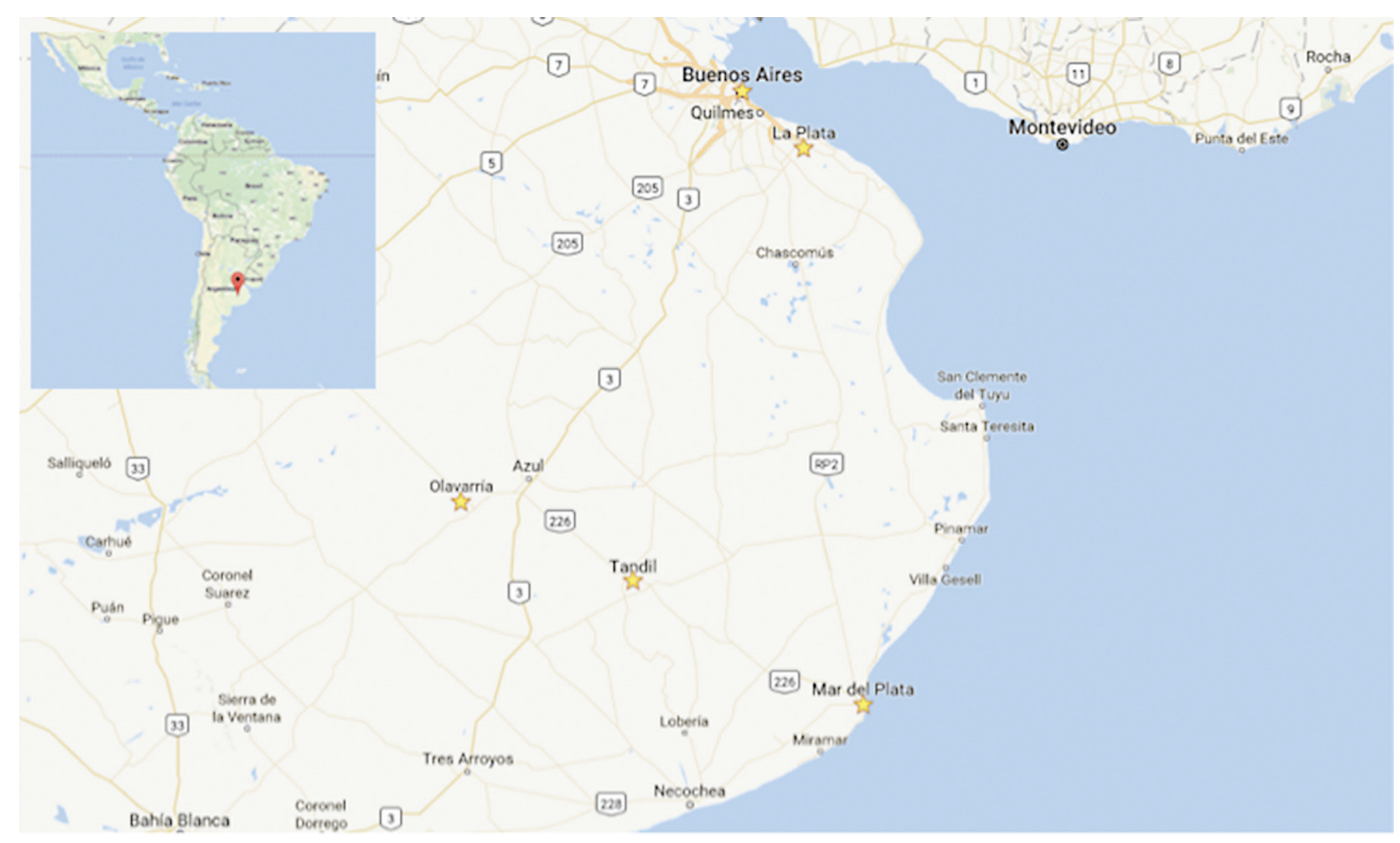

Figura 1: Ubicación de Buenos Aires (capital federal) y Olavarría, Tandil, La Plata y Mar del Plata en la provincia de Buenos Aires.

industrias, comerciantes y empleados públicos. El tradicional perfil laboral industrial se ha visto trastocado en las primeras décadas del siglo XXI, producto de ciclos de desempleo, por lo que diversos representantes políticos e instituciones han intentado actualizar ese perfil o renovarlo apelando a la necesidad de la "diversificación productiva" (Sosa, 2016).

Para este trabajo se realizaron 14 entrevistas en profundidad a profesionales de la salud (120 horas) y observaciones en diferentes ámbitos de atención sanitaria pública y privada (100 horas). Se seleccionaron los actores entrevistados a partir de elementos de su biografía personal relacionados con experiencias de migración y formación en otras ciudades. El acceso a los profesionales tuvo dos vías determinadas por el ámbito urbano de su ejercicio profesional. Por un lado, el acceso a profesionales asociados a la "clase media" 3 de la ciudad, del "centro" urbano, y la práctica desarrollada en el consultorio privado se dio a través de relaciones personales habilitadas por ser habitante y paciente de la ciudad y el campo sanitario que

3 Se trata esta de una expresión nativa de difusa y ambigua referenciación que a los fines de este trabajo sintetizaremos como la identificación que se esgrime para diferenciarse de la "clase baja" y sus condiciones de vida, es decir, el sector de trabajadores de la ciudad con empleos temporales e informales. 
investigo. Por otro lado, el acceso a profesionales vinculados a los "pobres" de la ciudad, la "periferia" urbana, y la práctica profesional comunitaria se dio a través de experiencias de extensión universitaria en barrios estigmatizados de la ciudad y al trabajo de campo que he estado realizando desde 2006 en torno a la atención de la salud mental en la ciudad media (Galarza y Gravano, 2012; Galarza, 2015).

A fines de siglo XX, y como resultado de la crisis económica y social neoliberal que asoló los municipios bonaerenses, la ciudad de Olavarría reconvirtió su imaginario identitario (Gravano, 2005). La generalización del desempleo hizo que la apelación a "capital del trabajo" y "del cemento" como mito fundante de la sociedad olavarriense (Gravano, 2005) se viera transformado en una serie de alternativas productivas, entre las que surgió Olavarría como "la capital regional de la salud" (Galarza y Gravano, 2012). Mis preguntas de investigación toman a este fenómeno de emblematización como incógnita y no mero contexto de transformación o cambio. Mi hipótesis es que aquello que se intenta capitalizar ${ }^{4}$ como identidad urbana proviene y requiere de una existencia cotidiana, es decir, de micro-emblematizaciones que se producen en las interacciones en las que sociabilizan los habitantes de la ciudad. El supuesto sociológico que subyace a esta aproximación al tema de la emblematización urbana es que esta funciona, por un lado, como producto $\mathrm{y}$, por otro, como base o fundamento de la praxis social de los profesionales. Al estudiar cómo, cuándo y con quién la praxis profesional se articula a una emblematización construida con narrativas míticas ordenadoras de lo sagrado y lo profano; en términos de quiénes son los "dioses" o las "eminencias" locales, nos estamos ocupando de la constitución social de la ciudad media en términos no literalmente religiosos, sino con un abordaje de economía política de su urbanización, el cual incluye la dimensión de las creencias (Singer, 1975; Topalov, 1979).

Para lograr el objetivo de investigación de entender el proceso sociocultural que estructura la constitución local del prestigio médico profesional y la emblematización urbana de la ciudad media como "capital de la salud" a nivel regional, he organizado metodológicamente el material de campo a partir de la recurrencia de ejes significativos. La triangulación de la información construida de este modo a partir de la etnografía se realizó en el marco de un proceso de sistematización del trabajo de campo (Guber, 2009; Hammersley y Atkinson, 1994). El interés analítico con el que se interpretó y organizó el material registrado en soportes diversos (diarios de campo, entrevistas grabadas) focalizó en los tropos recurrentes de la migración y la formación como experiencias sociales de la especialización urbana.

Las entrevistas en profundidad se hicieron a 10 médicos (6 hombres y 4 mujeres) especializados en el diagnóstico por imágenes, la clínica y la psiquiatría y 4 psicólogas. La apertura analítica a múltiples especialidades se realizó para poder ampliar la muestra y obtener mayor variabilidad etaria (60\% de casos de 30 años y 50 años y $40 \%$ de casos de más de 60 años) y de procedencia geográfica, de modo que contemplara tanto a los "nacidos y criados" como a quienes habían migrado de otras ciudades del país. Esta heterogeneidad de especialidades, procedencias y edades ha permitido identificar y construir variables e indicadores

4 Se utilizarán las cursivas para indicar un neologismo y/o categoría destacable desde el punto de vista analítico y las comillas para referenciar el discurso de actores. 
de las experiencias vividas como "de profesionalización" por parte de los actores que han servido para ampliar, desafiar y completar las aportadas por el marco teórico 5 .

El análisis y la sistematización del trabajo de campo llevaron a construir dos casos paradigmáticos a partir de la organización de las diferencias y recurrencias de los entrevistados y las diversas situaciones observadas.

Saúl es el tipo ideal del médico "de afuera" a los ojos de los olavarrienses que nacieron en la ciudad, el "porteño" o el que viene de la "gran ciudad". Reside en Olavarría desde hace por lo menos dos décadas, tiene entre 55 y 70 años, es decir, que nació en las décadas de 1940 y 1950 y tiene un promedio de tres hijos. $\mathrm{Su}$ formación y educación la adquirió en otra ciudad (por lo general Buenos Aires, La Plata o Córdoba), pero su desarrollo profesional-laboral lo realizó en gran medida en Olavarría. Es hijo de trabajadores con "buena posición", es decir, de padre ferroviario o petrolero y madre ama de casa y/o maestra. Al momento de su formación como estudiante de medicina, registró un modo liberal de ejercer la medicina (el que puede paga, y el que no, se queda sin atención) que le resulta completamente extraño a Karina, su arquetípica sucesora generacional, formada en el contexto de la proliferación de las obras sociales sindicales en una Argentina más típica del Estado de Bienestar.

Karina tiene entre 30 y 55 años, no más de dos hijos y, a diferencia de Saúl, es "de acá, no vino de afuera". Nació entre las décadas de 1980 y 1990. Dejó su casa paterna para estudiar, pues no había carrera de Medicina o Psicología en la región por aquel entonces ${ }^{6}$, y regresó una vez concluida su especialidad, es decir, luego de 10 años de formación universitaria, casada y con hijos. Las ciudades a las que migró son Buenos Aires, La Plata y Mar del Plata, siendo las dos últimas opciones más económicas que Buenos Aires. Su educación media y superior se produjo en las décadas de 1990 y 2000. Su formación como especialista se dio enteramente en la universidad pública y en hospitales públicos (en el caso de los médicos) o en prácticas de consultorio que se hacen ad honorem para adquirir experiencia (en el caso de las psicólogas). Al mudarse ya recibida a la ciudad, su práctica profesional suele oscilar entre el sistema público y el ejercicio privado.

Hemos construido estos casos a partir del material de campo para poder visualizar dos dimensiones claves de nuestras preguntas de investigación. En primer lugar, reconstruir el proceso histórico colectivo que permite la producción social de profesionales en la ciudad media (dimensión diacrónica). En segundo lugar,

5 He decidido dejar para otro trabajo el análisis de las diferencias que pueden distinguir y segmentar socio-económicamente a los grupos profesionales según la población de pacientes con la que interactúan. Esta decisión metodológica se realiza para poder cumplir con el objetivo de este artículo, que consiste, en términos generales, en comprender la relación entre especialización y emblematización urbana y la incidencia de la experiencia de la migración interurbana (especialmente, metropolitana) en el proceso de construcción local de prestigio de los profesionales de la salud.

6Cabe señalar que luego de funcionar 10 años como Escuela Superior de Ciencias de la Salud (desde 2006), la Universidad del Centro de la Provincia de Buenos Aires tendrá a partir de 2017 una sede oficialmente reconocida como Facultad de Medicina en la ciudad.

Cuadernos de Antropología 2016, 26(2), 27-50 / ISNN 2215-356X

http://revistas.ucr.ac.cr/index.php/antropologia 
comprender la producción imaginaria que contribuye a la segregación, en términos de individualización y prestigio, de estos especialistas en el proceso de urbanización (dimensión simbólico-ideológica).

Consideramos que el proceso histórico que viven Saúl y Karina corresponde a momentos diferenciados dentro de un gran ciclo que coincide con el neoliberalismo (Harvey, 2007). La profesionalización de Saúl se produjo en el marco de la última dictadura militar argentina (1976-1980). Este momento significa el comienzo de la implemetación de políticas neoliberales en Argentina. La profesionalización de Karina, en cambio, se dio en un período de democracia, incluidos períodos de neoliberalismo (1990-2003) y períodos de intentos de salida de la crisis (2003-2015).

\section{Obstáculos que el analista nativo de la ciudad media encuentra al abordar a la salud como un consumo colectivo y a la especialización urbana de los profesionales como un proceso colectivo}

La especialidad productiva de los profesionales de la salud es practicada a través de la atención y satisfacción de demandas individuales que se asocian a problemas de salud. Esas prácticas se apoyan en sistemas que se gestionan públicamente a través de administraciones estatales y empresas privadas. Así, la reproducción de la fuerza de trabajo de la ciudad media estudiada se encuentra, en términos sanitarios, asociada principalmente al hospital público municipal y a un conjunto extrahospitalario constituido por tres clínicas privadas y decenas de consultorios externos y laboratorios, donde los profesionales suelen asociarse por especialidad (por ejemplo, clínica, dermatología, oftalmología, etc.) para minimizar los costos fijos de su actividad. De esta manera, varios profesionales comparten no solo el inmueble, sino también la aparatología, el mobiliario, los recursos humanos (especialmente, secretarias y servicios terciarizados) y el costo de los impuestos y otros servicios públicos que son imprescindibles para desarrollar su actividad y que constituyen, asimismo, consumos colectivos urbanos gestionados por empresas nacionales y/o transnacionales y cooperativas locales de electricidad, agua, gas, telefonía e internet. Es así que los sistemas sanitarios, al igual que las unidades productivas industriales y otros servicios públicos, se benefician de estos "valores de uso complejos" o "efectos útiles de aglomeración" (Topalov, 1979, p. 9) que la ciudad ofrece a las actividades que en ella se instalan.

En términos estructurales, la organización de la atención sanitaria en su carácter de consumo colectivo urbano es resultado de la constitución histórica de la ciudad capitalista como un espacio de producción y reproducción socializado y universal. Sus componentes y su lógica de organización forman parte de las condiciones generales de la producción y circulación del capital y de la reproducción de la fuerza de trabajo, la cual debe su mantenimiento a "la existencia de medios de consumo socializados, así como de formación, de aculturación y encuadramiento" (Topalov, 1979, p. 25). El proceso de apropiación desigual de la riqueza social así producida requiere, en el capitalismo, necesariamente de procesos de distinción y segmentación social (Bourdieu, 1979). La distinción que se produce institucionalmente entre médicos y pacientes y que 
ha sido ampliamente estudiada en las prácticas de intervención en hospitales y consultorios (Conrad, 1982; Conrad y Schneider, 1990; Friedson, 1978) requiere de una comprensión que se ocupe no solo de la construcción de la autoridad terapéutica en el contexto del tratamiento médico, sino también de las condiciones "extramédicas" de su generación urbana.

Esta comprensión puede verse profundamente mediada y recurrentemente impedida por las propias categorías con que la analista aborda la realidad social de la que forma parte el fenómeno estudiado. En este sentido, la unidad ideológica o identidad local que mantiene cohesionado el proceso de urbanización a escala local, y en cuyo sentido común la analista ha sido socializada desde su más temprana edad, constituye un verdadero obstáculo epistemológico (Bachelard, 2000; Bourdieu, Chamboredon y Passeron, 2002) para la producción de conocimiento antropológico en y desde ciudades medias. La unidad ideológica a la que hacemos referencia se compone de una producción simbólica que tiene por único aparente modelo de lo urbano a lo metropolitano. Ariel Gravano (2016) llama metropolismo a esta "dependencia del imaginario hegemónico metropolitano" (p. 86). Como sucede en otras ciudades del "interior del país"7, los habitantes de Olavarría construyen a diario su identidad sobre la base de una producción simbólica e imaginaria que tiene por principal referente a la capital nacional. En esa comparación imaginaria, Buenos Aires aparece como teniendo atributos de gran tamaño, de avanzada modernidad y de progreso social que se condensan en frases locales recurrentes, tales como: “eso (Buenos Aires) sí que es una ciudá de veras, allá pasa de todo, esto (Olavarría) en cambio es un pueblo, acá no pasa nada"; tal como oímos decir a una empleada de un comercio de ropa de 25 años mientras atendía a una clienta con la que comentaban las noticias capitalinas que reproducía el televisor colgado de una de las paredes del local. Como sintetiza Cristina Leiro (2005) en su estudio sobre la imagen mediática como referente identitario en la ciudad media:

Aquellos que asignan a la ciudad de referencia -Buenos Aires- ciertas características positivas como diversificación de actividades culturales, servicios públicos eficientes, movilización social, etc. consideran a la ciudad que habitan -Olavarría- un pueblo por sus características negativas: escasa actividad cultural, servicios públicos deficientes, inmovilidad social, etc. (p. 75)

La co-constitución de las representaciones mediáticas que referencian lo metropolitano-lejano y lo pueblerino-local tiene por base la dimensión imaginaria. Esta dimensión imaginaria se nutre de la emblematización urbana, entendida esta como la producción simbólica de imágenes vigorosas distintivas de un centro urbano particular (Gravano, 2005; Boggi, 2005). El proceso de emblematización "supone una pretendida homogeneidad que oculta un espectro de intereses dispares y antagónicos respecto a la cuestión del para quién de la ciudad misma" (Gravano, 2016, p. 82). La homogeneización da lugar así a una pretendida e imaginada unidad identitaria que es actualizada cada vez que el emblema es utilizado con un sentido práctico (Bourdieu, 2007).

7 Expresión que designa al espacio geográfico por fuera de la capital federal argentina, es decir, el 99, 99\% del territorio nacional. La superficie de la capital federal es de $203,3 \mathrm{~km}^{2}$ y la del territorio nacional es de $2780400 \mathrm{~km}^{2}$. 
Por ejemplo, el espacio significacionalmente construido como "muerto" por los olavarrienses, esto es, sin vida cultural ni progreso, ha tenido paradójicamente una agitada y sangrienta dinámica histórica que se vincula al proceso de organización del Estado-Nación y al genocidio de los pueblos originarios que las oligarquías agroexportadoras y burguesías independentistas y nacionalistas del siglo XIX profundizaron al reclamar soberanía como nación a la corona española. La producción social de formas espaciales (Castells, 1974, p. 27) en la región pampeana se encuentra, pues, íntimamente ligada a la llamada "conquista del desierto", un proceso de conquista de tierras aborígenes que los primeros gobernantes del incipiente EstadoNación argentino representaban como salvajes y/o vacías. La identidad cívica de esas formas espaciales asociadas a las campañas militares son propias de una especie de "comunidad de los guerreros" (Weber, 1979, p. 993) que fueron, en la pampa argentina, quienes posibilitaron la apropiación y valorización de las tierras de la región. Estudios arqueológicos, históricos y antropológicos señalan que los fortines creados en esta llanura, como puntas de lanza de la civilización contra el indio ${ }^{8}$, funcionaban en términos urbanos más como antiguos centros débilmente amurallados con una gran actividad de intercambio con la población originaria que como meras empresas "civilizatorias" (Mandrini, 1988). Esa combinación de ciudad antigua (fortín) y posteriormente ciudad comercial intermediaria entre la ciudad puerto de Buenos Aires y el sudoeste del territorio fueron los cimientos de las modernas ciudades de rango medio del centro bonaerense que nos ocupan aquí.

La unidad del mito integrador (la civilización, el progreso) al que el emblema se fija es en realidad un proceso de construcción de hegemonía que busca homogeneizar las diferencias y solidarizar la expropiación urbana. Diversos estudiosos de las ciudades han señalado que la constitución de lo urbano se realiza mediante la institucionalización de sistemas y actores sociales con funciones específicas. Es el Estado una de las principales instituciones urbanas, y los gobernantes, los mercaderes, los burócratas, los guerreros y los religiosos, sus principales especialidades profesionales (Childe, 1973; Mumford, 1979; Singer, 1975).

Los militares, terratenientes y abogados ilustrados eran el grupo social que motorizó la fundación de las ciudades en esas tierras imaginariamente construidas como "descampadas" e "inhóspitas". Siguiendo una lectura histórico-estructural de este proceso, podría afirmarse que así como las ciudades-fortines eran "la punta de lanza de la civilización" de aquellos próceres y militares, las ciudades medias de la actualidad son "la capital" territorial del desarrollo capitalista industrial. En ellas ya no son los militares los profesionales que se encargan de la conquista y la urbanización, sino las capas profesionales que, como resultado y profundización de esa urbanización, han expandido y especializado sus funciones urbanas en sistemas como el productivo, el gubernamental, el educativo, el sanitario, el judicial, el de aprovisionamiento y distribución y el de comunicaciones.

8 Baste referenciar una publicación con la que la ciudad celebraba el centenario de su fundación, donde se citan las palabras de Estanislao Zeballos describiendo a Olavarría en 1879: "Olavarría, última población civilizada de la comarca, estaba rodeada de indios y la tienda era el punto de refugio del pobre y escaso vecindario, en los días en que el salvaje lo despertaba con su estridente alarido. Su dueño -el 'pulpero'- era español, hablaba la lengua de los indios mejor que la propia y comerciaba con ellos en el cambalache de pluma, cerda y tejidos pampas por artículos de consumo y vicios” (Municipalidad de Olavarría, 1968, p. 32).

Cuadernos de Antropología 2016, 26(2), 27-50 / ISNN 2215-356X

http://revistas.ucr.ac.cr/index.php/antropologia 
Puesto que con este trabajo se busca reconstruir y comprender explicativamente los procesos identitarios e imaginarios de ciudades de rango intermedio, cuya emblematización dentro de los sistemas de representaciones simbólicas definen histórica y culturalmente a este tipo de centros urbanos, el punto de partida planteado aquí es el contraste entre los fenómenos metropolitanos y los de rango medio, y su utilización diferencial en cada contexto particular. Partimos del supuesto de que hegemónicamente se suele preconcebir lo urbano desde modelos de escala metropolitana, tanto a nivel teórico como de sentido común $\mathrm{y}$, sobre todo, en la perspectiva preponderante de la gestión político-institucional. No obstante, en nuestro caso, el abordaje de lo "urbano medio" se ve en la situación de tener que dialogar tanto teórica como fenomenológicamente con lo "urbano metropolitano", ya que, tanto en el discurso de los actores como en el de los referentes del campo de la antropología urbana, lo metropolitano y lo medio aparecen no solo como "contexto", sino como "valor", asociado a procesos de distinción. La relación estructural entre estas escalas urbanas ha sido estudiada por Ariel Gravano en sus diversas manifestaciones: “(La) dependencia metropolitana se ampara conceptualmente en el hecho de que se suele preconcebir lo urbano desde un modelo de escala metropolitana, tanto a nivel teórico cuanto de sentido común y en la perspectiva preponderante de la gestión político-institucional” (Gravano, 2016, p. 86).

Por tanto, se vuelve necesario un abordaje especifico de la ciudad media que se haga proyectable a la comprensión de las identidades locales y al distanciamiento con perspectivas hegemónicas que se trasladan mecánicamente a este tipo de ciudades. En este sentido, se considera la referencia de lo metropolitano que hacen los actores como una representación a desnaturalizar y problematizar desde los propios procesos socio-históricos referidos por ellos.

El desafío consiste entonces en "derribar los obstáculos amontonados por la vida cotidiana” (Bachelard, 2000, p. 21). Para hacerlo, es preciso concebirlos como una dialéctica de obstáculos que se descubren e invisibilizan dinámicamente más que como una entidad monolítica. Dado que como advierte Bachelard (2000) "al tratar de desentrañar un obstáculo nos encontraremos con otro opuesto" (p. 23), es frecuente que el investigador oponga dicotómicamente la metrópolis a lo local. Sin embargo, lo local es parte constitutiva de la elaboración imaginaria de la metrópolis en la ciudad media, no su mágica superación. En este sentido, el "metropolismo" al que hicimos referencia más arriba es vindicativo de "la propia identidad local extensa... dentro de la dialéctica de lo universal y lo local, sobre todo cuando el modelo hegemónico naturaliza una concepción abstracta de lo urbano como lo metropolitano" (Gravano, 2016, p. 86).

En el caso que aquí se presenta de los profesionales de la salud, el "metropolismo" aparece asociado al opacamiento de otros procesos sociales que han hecho posible su especialización profesional, tales como la experiencia migratoria y el carácter constitutivo de su valorización local simbólica y económico-profesional en la ciudad media. En ese proceso de valorización que estos migrantes profesionalizados van adquiriendo en su tránsito por el centro de la región pampeana y de ciudades de mayor tamaño que se encuentran en sus límites geográficos y que son importantes centros administrativos provinciales o nacionales, el estado municipal cumple un papel muy importante.

Cuadernos de Antropología 2016, 26(2), 27-50 / ISNN 2215-356X

http://revistas.ucr.ac.cr/index.php/antropologia 


\section{La capital de la salud ${ }^{9}$ en la que se pierden y se ganan elecciones con tomógrafos}

Como mencionáramos más arriba, en la actualidad, la imagen emblemática de Olavarría está siendo reconvertida hacia el sector servicios, especialmente al de salud. En palabras de quien fuera su intendente municipal cinco veces (de manera no consecutiva entre 1983 y 2007), Olavarría "está llamada a constituirse como gran plaza médica y de la salud regional" (intendente Helios Eseverri [Municipalidad de Olavarría, 2007$, p.7] $)^{10}$. En estos términos, su primer tomógrafo fue adquirido por el hospital municipal en 1986. Los entrevistados de más edad referencian que su compra provocó un gran debate público en torno a la necesidad o no de este tipo de inversiones y a la sospecha de corrupción en las licitaciones. El propio intendente habría reconocido, según el testimonio de un médico promediando los 60 años que trabajó en la gestión municipal hospitalaria en los años 80, que este hecho "le costó la intendencia" en 1987". Desde entonces, la adquisición de aparatos de alta complejidad ha estado presente en los debates político-sanitarios locales, tanto porque son de alto costo para las arcas municipales cuanto porque suscitan discusiones en torno al tipo de hospital que la ciudadanía olavarriense debería, merecería o querría tener.

Tener un buen hospital público municipal es uno de los orgullos y deseos de gran parte de la población olavarriense, aún de aquella que se atiende en clínicas privadas. Funciona como una especie de monumento emblemático y mítico que suele asociarse no tanto al desempeño de sus trabajadores habituales como a la capacidad del intendente de controlarlos, tal como sintetiza esta pensionada de 72 años que al jubilarse dejó de transitar por el sistema privado de atención y comenzó a frecuentar el ámbito hospitalario: "Cuando estaba el viejo Eseverri estaba todo limpio y en orden, el viejo se aparecía a las 4 de la mañana de sorpresa a ver cómo andaba todo... no volaba una mosca... ahora en cambio, nadie controla nada". Llamativamente, la "clase media" olavarriense, esto es comerciantes, profesionales y trabajadores calificados con acceso a clínicas privadas, no son indiferentes a las inversiones que se hacen en el hospital. Suelen asociar "tener un buen hospital" con "una ciudad moderna", "no como esas del conurbano que están colapsadas, y no tienen ni para gasas", como nos compartió una contadora de 42 años que trabaja en el municipio.

Quizás por esta valoración positiva de la opinión pública los anuncios de inversión hospitalaria suelen darse en momentos políticos de relevancia electoral. En 2013, antes de la renovación de bancas legislativas, el ejecutivo municipal anunció la futura adquisición de un segundo tomógrafo en el hospital local por un valor aproximado de 5 millones de pesos. Los medios locales registraron detalladamente el proceso de la licitación, desde su comienzo hasta la definitiva adquisición del aparato, pasando por la adaptación edilicia del hospital para su funcionamiento (El Popular, 2013, 2014). La compra la realizó el nuevo intendente, hijo

9 Este término lo tomamos del discurso del intendente antes referenciado. Utilizamos la cursiva para hacer mención al carácter extendido de un término emic cuya autoría popular colectiva excede a la persona del intendente, aunque este en sus discursos públicos lo utilizara como propio. Destinamos las comillas a la cita textual de discurso de actores.

10 Para ampliar la referencia, se puede consultar Galarza (2015).

11 Entrevista a encargado (médico especialista, 64) del área hospitalaria en la única derrota electoral de Helios Eseverri.

Cuadernos de Antropología 2016, 26(2), 27-50 / ISNN 2215-356X

http://revistas.ucr.ac.cr/index.php/antropologia 
del intendente que había comprado el primer tomógrafo anteriormente mencionado. El titular de "Prevención y Atención Sanitaria" celebraba la decisión de licitar el segundo tomógrafo computado del hospital en agosto de ese año, de la siguiente manera: "Estamos hablando de tecnología médica aplicada al servicio del vecino. Va a mejorar nuestra atención, vamos a ser de los pocos hospitales municipales que cuenten con dos tomógrafos". (R. Borzi, Secretario de Prevención y Atención Sanitaria de Olavarría [El Popular, 2013]). Esta adquisición se sumaba a otra reciente incorporación de un aparato de diálisis, para el tratamiento de insuficiencia renal aguda; y la adquisición de una torre de cirugía laparoscópica (El Popular, 2013).

Helios y José Eseverri, padre e hijo, han sido los intendentes de la ciudad de Olavarría desde la década de 1980. Helios Eseverri ocupó este cargo en cinco ocasiones (1983-1987, 1991-1995, 1995-1999, 1999-2003, 2003-2007). José Eseverri lo hizo en dos (2007-2011 y 2011-2015). Estos 32 años de gobierno adquieren la designación de "eseverrismo". En ellos se condensan dos de los elementos más importantes que estructuran la organización política municipal: el parentesco y la re-elección de personas conocidas por los vecinos.

El rumor público (Kapferer, 1989) que me fue expresado por varios profesionales (médicos y psicologas) que trabajaron en el hospital municipal en las décadas de 1980 y 1990 fue que "el tomógrafo le hizo perder la intendencia a (intendente]) Eseverri” (G.R., médica clínica, 62 años). Para estos profesionales, el único fracaso en las elecciones municipales del eseverrismo hasta el 2015 se vinculaba y dependía directamente de gestión hospitalaria y más precisamente de que "la gente no estaba preparada para algo tan moderno", en la hipótesis del médico especialista encargado del área que alentaba la adquisición de la tecnología. Una buena gestión hospitalaria significaría una buena gestión de gobierno, de acuerdo con expresiones que con frecuencia asocian la figura de Eseverri casi exclusivamente con una buena administración del hospital municipal, como "lo único que hizo bien el intendente a pesar del resto". (C.G., 58, vecina de Olavarría, usuaria frecuente del Hospital y votante de Eseverri).

El hospital es entonces emblematizado por el imaginario local, en un proceso de metaforización y representación simbólica en el que ciertos elementos se deshistorizan, naturalizándose, y otros se ensalzan para fijar asociaciones semánticas dentro del imaginario local. La historia política de los agentes y las instituciones se van así reconvirtiendo, en este proceso sociocultural, configurando una noción de gestión pública en el plano local olavarriense fuertemente asociada a lo administrativo y a lo sanitario.

Resulta interesante, por tanto, la particular vinculación que realizan los intendentes entre la gestión política, la política pública sanitaria y el imaginario urbano sobre la ciudadanía -concebida en su discurso exclusivamente como votantes- para explicar su propio fracaso eleccionario. De acuerdo con su propio diagnóstico imaginado, el problema estaría al nivel de los imaginarios de la gente, puesto que la razón final del rechazo ciudadano al tomógrafo estaría en estrecha vinculación con el tipo de ciudad que Olavarría debería imaginarse siendo para darse al progreso, en vez de resistirse a él: 
Creemos que, en buena medida, las elecciones de 1987 las perdimos justamente por ese debate, ya que se sostenía que era impagable, que no era la función del Estado y que era una medicina extraña para una ciudad como la nuestra. Pero el tiempo fue haciendo que el pueblo volviese sobre sus pasos y nos terminara dando el respaldo que obtuvimos en 1991 (H. Eseverri, comunicación personal, 25 de agosto de 1999).

Este testimonio señala que las imágenes y metáforas con que se identifica, se reconstruye y se designa a la medicina y a la salud en una ciudad de rango medio son de gran relevancia política. ¿Qué quiere decir el intendente con "una ciudad como la nuestra" (Olavarría)? ¿Cómo es esa medicina (de alta tecnología) "extraña" a ella? Parece pues darse aquí la construcción de un espacio significacional que reconstruye el tradicional dualismo con que se suele definir a las ciudades intermedias en tanto no metropolitanas, cuasirurales y atrasadas, al mismo tiempo que se asocia a las metrópolis con lo urbano y lo moderno. De modo imaginario, lo que el discurso del intendente plantea es una mediación tecnológica entre este espacio atrasado y aquel otro lleno de progreso, donde el comprar aparatología es un modo de acercarse a ser más urbanos y modernos. La cuestión de la tecnología en el campo sanitario de la ciudad media se asocia por tanto a las relaciones de "competencia" con que se cree que la ciudad es interpelada a actuar.

La reconstrucción antropológica del proceso de emblematización señala que la identidad urbana que el imaginario institucional produce y reproduce sobre la ciudad de Olavarría no solo se despliega diacrónicamente (lo que éramos en el pasado y deberíamos ser en el futuro), sino que también lo hace en un sentido sincrónico (lo que son otros y somos nosotros paralelamente). Es decir, no solo se acumulan (metafóricamente hablando) imágenes de ciudad que dan apoyo y anclaje a nuevas representaciones y configuraciones simbólicas en un sentido histórico, sino que también esos anclajes tienen en cuenta representaciones de contextos y objetos que los actores construyen como extemporáneos, "por fuera de lo local”, pero en relación con él en un mismo momento. Esta visión emic de lo local (ahistórica pero relacional) resulta crucial como punto de referencia para centrarnos en el analisis de lo "medio" y lo "metropolitano" no solo como un sistema de valores que se asocia al metropolismo, sino como un proceso social de valorización que se asocia a la urbanización.

\section{Profesionales y especialización técnica}

Existe una estrecha relación entre el Estado y la salud, y entre los profesionales de uno y otro campo. Saúl (uno de los primeros "radiólogos"12 de la ciudad, criado en un barrio de clase trabajadora de la Capital Federal, y formado en la Universidad de Buenos Aires) expresa muy claramente el vínculo que se produce

12 Término en desuso para referirse a los médicos que hacen diagnóstico por imágenes. 
entre la necesidad de la tecnología para su desarrollo profesional y el rol jugado por el Estado en su satisfacción. Luego de mudarse a Olavarría, Saúl comenzó a asesorar al intendente en cuestiones de aparatología. Trabajó en el hospital municipal ejerciendo la medicina y la docencia durante las décadas de 1980 y 1990. Luego de la década de 2000, se dedicó exclusivamente a la atención de pacientes en los consultorios privados que instaló junto a otro colega de su especialidad. Evocando aquellos años de juventud, trabajo en el hospital y gestiones de gobierno, reflexiona:

Comprar equipamiento era un estímulo para nosotros y nos sacaba de esa diferencia con los de Buenos Aires. Cuando me vine a Olavarría, me quedó el resabio de la desconexión. Por estar en Olavarría vivía atrasado 4 años. De eso me daba cuenta cuando iba a congresos o leía revistas especializadas. Después Eseverri me ${ }^{13}$ compró el tomógrafo y ahí me puse a tiro ${ }^{14}$.

Este testimonio permite visualizar las estrechas relaciones infraestructurales e identitarias que vinculan a las instituciones político-administrativas de la ciudad media con la capa de profesionales médicos. Los actores sociales cuyos medios de producción son los costosos aparatos (ecógrafos, tomógrafos y resonadores) dependen, en ciertos momentos de su carrera, o a lo largo de todo su recorrido profesional, de que el Estado se haga cargo de su adquisición. Simultáneamente, los políticos utilizan estos recursos de gran valor público para legitimar sus gestiones de gobierno. A diferencia de otras especialidades médicas, la del diagnóstico por imágenes depende exclusivamente de la manipulación de aparatología. En consecuencia, la reproducción de este tipo de profesionales está intrínsecamente ligada al acceso a ellos. Su altísimo costo hace que especialistas como Saúl trabajen durante varios años en el hospital público, donde el Estado es el que adquiere la tecnología, o que promediando su carrera, instalen una sociedad con colegas con la que afrontan colectivamente el costo de la inversión.

Esta especialidad se caracteriza, según las propias palabras de los médicos, por "no tener que lidiar tanto con pacientes, a diferencia de la 'clínica', sino más bien por "entender los aparatos y saber leer bien las imágenes". Este aspecto específico genera la presión entre ellos de una "constante actualización técnica", pues la base de su desempeño no se halla tanto en el cuerpo humano como en el dispositivo que lo lee. La exigencia de la actualización es amortizada en la práctica por otra ulterior especialización, que consiste en la combinación entre la técnica y el órgano corporal: "finalmente, uno se termina especializando en una sola cosa: o ecografía, o tomografía, o resonancia, así como, en un tipo de órganos: o estomago, o cabeza, o colon, por dar un ejemplo", como nos explicó un especialista de 58 años.

13 Se refiere a que al intendente compró el tomógrafo para el hospital donde él era jefe de servicio. La utilización del prefijo personal "me" connota una relación de familiaridad y compromiso afectivo con el equipamiento y con el líder político de la ciudad que interpretamos como una relación metonímica que enlaza afectivamente al emblema de la ciudad de la salud, al medio de producción profesional y a quien podríamos considerar el patrón público de la ciudad: el intendente.

14 "Ponerse a tiro" es una expresión cotidiana utilizada para decir "ponerse al día o actualizarse sobre algo".

Cuadernos de Antropología 2016, 26(2), 27-50 / ISNN 2215-356X

http://revistas.ucr.ac.cr/index.php/antropologia 
En el caso de la psiquiatría y la psicología sucede algo semejante. Las psicólogas locales que se forman en La Plata, Mar del Plata o Buenos Aires suelen también especializarse. Sus unidades de intervención son ciertos grupos de edad (niñez, adolescencia, adultos) o ciertos problemas (adicciones, trastornos de personalidad, crisis de angustia, depresión, ansiedad). Los profesionales de la especialidad "psi" parecen también establecer una dinámica en la que intercalan momentos laborales en el "sector público" (hospital, escuelas, poder judicial, granjas de rehabilitación) con otros en el sector privado, instalando su propio consultorio. Suelen "tener un pie" en cada ámbito, debido a que la práctica privada no resulta tan establemente redituable. Las razones esgrimidas para la baja rentabilidad en el sector privado son principalmente dos: 1) la gran oferta de profesionales que se disputan la demanda de una clientela de pacientes que se mantiene estable, y 2) la dependencia monetaria de las obras sociales que "no cumplen con los pagos" o que "pagan con mucho atraso y muy poco", como señalaron profesionales de la salud de todas las especialidades y edades. En cambio, en el sistema sanitario estatal, instituido a través de una multiplicidad de estructuras municipales, provinciales o nacionales, el salario es "fijo, y seguro", y en las "épocas malas" (idem), en familias conformadas entre profesionales, comerciantes y/o trabajadores, el único ingreso estable del hogar es el del profesional del sistema público.

De este apartado se desprende que el elemento más comúnmente asociado a los profesionales por la emblematización urbana de los imaginarios político-institucionales es el de su especialización técnica. Esta dimensión suele ser considerada de primera importancia por los agentes estatales y médicos, para cumplir con las funciones públicas sanitarias. Sin embargo, como veremos, existe también otro tipo de especialidad que se asocia a los profesionales locales. Se trata del modo en que los actores viven socio-culturalmente la ciudad a través de representaciones y valorizaciones que ordenan la relación estructural que los otros habitantes de la ciudad de rango medio (los pacientes) tienen con estos especializados habitantes (los médicos).

\section{Trayectorias migratorias}

Las residencias temporales y/o definitivas en otras ciudades son experiencias habituales entre los profesionales locales, pues suelen migrar para estudiar una carrera en las ciudades universitarias de Buenos Aires, La Plata, Mar del Plata, o desde hace poco más de una década, Tandil. Muchos abandonarán, cambiarán de carrera, ciudad, o se pondrán a trabajar. Otros, en cambio, regresarán una vez terminado el periodo de estudio, "con el título bajo el brazo", como suele decirse popularmente.

Los estudios sobre migración han desarrollado un amplio corpus de trabajos asociados a la pobreza que se ha traducido en un extendido interés teórico por entender las "estrategias de supervivencia" del migrante en su lugar de destino y sus redes de solidaridad y reciprocidad para adaptarse a los nuevos ámbitos urbanos (Arizpe, 1985; Balán, 1982; Lomnitz, 1975). Sin embargo, han sido más escasos los estudios sobre migración que han intentado concebir a la sociedad expulsora y receptora como formando parte de una misma unidad. Resulta imprescindible, en este sentido, mencionar a las investigaciones de la Escuela de 
Manchester, en las cuales se muestra, a partir del análisis de las prácticas de los migrantes, cómo el flujo y la relación entre aldea y ciudad es continuamente producido, pues las relaciones entre estos ámbitos permiten la reproducción de los aldeanos que se trasladan a la ciudad industrial en busca de trabajo. Sus etnografías constituyen tanto un estudio de la migración rural-urbana en el centro y sur de África como una comprensión profunda del capitalismo imperial en esa región del mundo a mediados del siglo XX (Gluckman, 1940; Mitchell, 1999). La desnaturalización de la idea de la migración como un mero cambio de residencia permite visualizar la especificidad de este proceso en migrantes profesionales. Abordar la migración como un proceso social permite comprender mejor la reproducción de los trabajadores de la salud y su papel en la reproducción de la fuerza de trabajo de la ciudad media. A este respecto, el análisis del material etnográfico señala que es posible tipificar las experiencias de migración de los profesionales de la salud que trabajan en la ciudad media en dos tipos: 1) de la capital (incluida su región metropolitana) a la ciudad media, y 2) de la ciudad media como estudiante a la ciudad media como profesional con la mediación de la capital en la formación profesional. Tomando como eje la circulación profesional por ciudades medias, capitales de provincia y metrópolis-capital nacional, las tipificamos del siguiente modo:

\section{Migración tipo 1: el desplazamiento de la metrópolis a la ciudad media}

La instalación de Saúl en Olavarría se produjo a los 26 años, en 1973, al momento de su formación en la especialidad (lo que hoy llamaríamos la residencia). En ese entonces, recuerda, que buscaba trabajo mientras se formaba en el actual Hospital Güemes: "El jefe del 'francés' (se refiere a otro hospital) que estaba casado con una olavarriense me sugiere venir a Olavarría a probar, porque había falta de radiólogos, así que arranqué viniendo dos días a la semana mientras seguía viviendo en Capital y terminaba la especialización".

Pocos meses después, tomó la decisión definitiva de instalarse en Olavarría, sobre todo por “estabilidad emocional", es decir, para encontrar "tranquilidad" tanto en un sentido laboral como familiar. Según evoca, “además, (estar en) capital era complicado por la política, no era momento para ser neutral". Luego de unos meses de prueba, decidió instalarse definitivamente en la ciudad con su esposa, donde ambos residen hasta la actualidad con sus hijos.

\section{Migración tipo 2: el desplazamiento desde la ciudad media hacía la capital (nacional o provincial) y desde esta a la ciudad media}

Karina, de 32 años, nacida en un pueblo a $20 \mathrm{~km}$ de la cabecera del partido, migró a La Plata (capital de la provincia) para estudiar medicina en esa ciudad entre 1999-2006 y realizar una residencia en su región metropolitana entre 2007-2011. Al final de esta, pocas semanas antes de rendir su examen de médico especialista, se instaló en Olavarría con su marido, también médico, y sus dos hijos. Allí ejerce su especialidad 
tanto en el hospital público como en clínicas privadas. Su motivo para instalarse en Olavarría resultó ser la tranquilidad de una muy buena oferta laboral para su marido. Reconoce que el haber regresado a Olavarría le costó un poco en términos de sociabilidad, en tanto extrañaba a sus amigos de residencia y "la vida en La Plata", una "etapa de la vida que se terminó, porque ahora, cuando vamos, tampoco encontramos a nadie allá, muchos se fueron y otros están ocupados trabajando".

A pesar de las diferencias generacionales entre Saúl y Karina, -uno cerca de jubilarse y la otra "recién empezando"-, ambos comparten un cierto tipo de relato profesional de sus experiencias migrantes. Mientras que otros grupos de trabajadores tienen una experiencia dolorosa de la migración, cargada de penurias económicas, ellos refieren un importante elemento de voluntad, decisión y ponderación de intereses tanto económicos ("ganar buena plata") como sociales ("la tranquilidad") en su decisión de migrar de ciudades más grandes hacía Olavarría.

\section{La valorización profesional}

Existe un tema de explícita e implícita presencia en la narrativa con que los médicos explican su historia, vinculado a la competencia profesional. Esta se encuentra asociada a dos dinámicas: la de la competencia profesional como habilidad adquirida por un individuo, y la de la competencia intraprofesional e interurbana. Cuando participan en congresos nacionales e internacionales, algunos médicos disfrutan de hacerlo en concursos de diagnóstico de casos raros. En estos eventos se suele elegir un caso de difícil diagnóstico que genera opiniones diversas. Los médicos participan hipotetizando causas del cuadro patológico y las escriben en una planilla. El ganador que acierta se lleva un libro de medicina de regalo. Para algunos médicos promediando los 60 años y que provenían de ciudades capitales y/o universitarias, esas competencias "son las pocas satisfacciones que uno tiene a nivel profesional". En ellas se exhibe la competencia profesional como en una especie de vitrina, ante los colegas: "Por estar en el interior yo tenía miedo de estar desconectado pero ahí en las competencias nos dábamos cuenta que no éramos crotos ${ }^{15}$, éramos igual a los de Buenos Aires", cuenta uno de ellos orgullosamente.

El camino profesional también se constituye del circular por espacios urbanos significativamente diferenciados de la metrópolis y de la ciudad media de referencia del hablante. Se genera así una escala de valoraciones urbano-profesionales en la que la propia ciudad se imagina como siendo el centro positivo de la competencia con otras ciudades o poblados que se envisten de rasgos claramente negativos. De los testimonios surgen dos localidades cercanas que se oponen en este sentido a Olavarría. Se trata de dos ciudades más pequeñas en términos poblacionales e infraestructurales: Azul y Lamadrid. De acuerdo con algunos médicos y psicólogas olavarrienses en Azul, "los médicos son más nariz para arriba” (engreídos), lo cual se

15 La palabra "croto" refiere en Argentina a alguien vagabundo, pobre, degradado. 
reflejaría en una cierta actitud "sado", es decir, autoritaria hacía los pacientes. En cuanto a Lamadrid, por su parte, un poblado de aproximadamente 8000 habitantes que se encuentra a aproximadamente $100 \mathrm{~km}$ de Olavarría, expresan que "está todo muerto, no vale la pena ir ahí, ni económica ni profesionalmente". Entre los médicos más jóvenes que no han desarrollo practicas en otros lugares que la de formación y residencia, en cambio, Olavarría aparece como una ciudad muy competitiva, tal como lo expresa una joven médica de 30 años: "acá es como que están todos los médicos compitiendo, allá (se refiere a la ciudad universitaria de formación) éramos más compañeros". Esta valoración del compañerismo hace referencia a la situación de residente, una especie de liminalidad entre ser estudiante de medicina y ser médico.

Cabe señalar que la vivencia de la competencia profesional difiere también en relación con otra variable que compone los dos tipos de migración señalados. Quienes han tenido experiencias de migración tipo 1 tienen mapas mentales de los "lugares muertos" adonde "no vale la pena ir" profesionalmente y los lugares competitivos, que aportan un valor de distinción y prestigio a quienes de otra manera sino serían profesionales degradados ("crotos"). El espacio significado imaginariamente como "vivo" es aquel que contribuye a la actualización (modernización) del profesional y por tanto al acrecentamiento de su prestigio. Paradójicamente, quienes han experimentado la migración tipo 2 encuentran que la ciudad donde comienzan a desempeñarse profesionalmente (Olavarría) es mucho más competitiva que aquella en donde se formaron y pasaron sus años de estudiantes universitarios. Esta producción de sentido es más habitual entre quienes estudiaron en ciudades universitarias de la provincia de Buenos Aires, como La Plata o Mar del Plata, que entre quienes estudiaron en la capital federal.

\section{Más laburante que prócer}

Un elemento importante en el relato de los actores en torno a su crecimiento profesional, es decir, su valorización, es la espera del recambio generacional que permitiría el aumento de los ingresos. Por ejemplo, en el Hospital Güemes, un hospital general provincial situado en la localidad bonaerense de Haedo, a escasas cuadras de la capital federal, donde hacían su residencia muchos médicos formados en el área metropolitana, existía lo que se llamaba "concurrentes": médicos jóvenes que trabajaban ad honorem durante años, "esperando a que se jubile un viejo", tal como nos relató un médico formado en la década de 1960 en ese hospital. Estos profesionales jóvenes debían dedicar un amplio período de tiempo a la formación sin remuneración. Desde hace aproximadamente unas 3 décadas esto habría cambiado. La década del '70 habría sido, según el testimonio del mismo médico, una época bisagra para la medicina, pues con la aparición de los sindicatos y las obras sociales, desde su punto de vista, esta "se socializa". En los años previos a esa socialización, que podríamos denominar como los años liberales de la práctica médica, los médicos ostentaban más privilegios. Los profesionales de más edad han visto incluso a médicos que cobraban (a los pacientes) por año: "esos médicos ganaban fortuna", tal como rememoraba haber visto un médico recién llegado a Olavarría en la década de 1970. 
Lo que este actor designa como la "socialización" de la medicina es un proceso de ampliación de la cobertura médica de la clase trabajadora que se da en las últimas tres décadas del siglo XX. A diferencia de aquel médico liberal, cuyos ingresos dependían mayormente de la oligarquía local, que le retribuía sus servicios con un gran pago anual y animales para comer, y que construía un gran reconocimiento de tipo patriarcal que alimentaba su prestigio en la localidad, el médico de la segunda mitad del siglo XX depende de un salario -concebido como "honorarios"- que le es retribuido a partir de los aportes de los trabajadores que organizan estos fondos en mutuales y obras sociales. Este cambio es metaforizado por los médicos con un: “ahora sos más un laburante que un prócer", señalando que la proletarización en la ciudad media llegó no solo a los pacientes, sino también a los profesionales.

\section{La razones económicas de la decisión de migrar}

De acuerdo con el aspecto económico, las apreciaciones de nuestros informantes divergen, quizás por motivos etarios. Para los mayores, antes los médicos "ganaban mejor". En relación con lo que cobran los profesionales en distintas ciudades, muchos suponen que de trabajar en Buenos Aires ganarían más, pero que esa plata "se compensa con la tranquilidad que hay acá, allá se vive muy mal", como nos explicó una psicóloga de 40 años que cursó sus estudios universitarios en esa ciudad y ejerce la profesión en Olavarría desde hace aproximadamente 10 años. Los especialistas jóvenes de diversas especialidades suponen que de haberse quedado en la ciudad donde estudiaron (La Plata, Buenos Aires, Mar del Plata), estarían ganando la misma cantidad de dinero que en Olavarría, pero trabajando mucho más. En su cálculo económico de las posibilidades de residencia y empleabilidad, resulta una opción racionalmente lucrativa mudarse a Olavarría para desarrollar su profesión. Muchos médicos además tienen hijos profesionales (contadores, ingenieros, abogados, médicos, arquitectos) que migran también a ciudades con universidades para formarse y regresar a Olavarría para ejercer la profesión y constituir una familia. El hijo del intendente que compró el segundo tomógrafo tuvo una trayectoria migratoria de este tipo: estudió Derecho en La Plata y residió un tiempo en esa ciudad mientras era senador provincial, hasta que regresó para instalarse en Olavarría y suceder a su padre en su carrera política.

De esta forma, representaciones semejantes operan con respecto al tipo de paciente con que se encuentra un médico que llega a Olavarría. Los entrevistados sostienen que en Olavarría la gente es más respetuosa que en la capital: "allá sos un laburante más, acá en cambio sos una especie de semi-dios, te tratan distinto acá", como nos explicó una joven médica de 35 años que destinaba 2 horas diarias a llegar desde Buenos Aires a una ciudad de la región metropolitana al hospital donde realizaba sus prácticas. Llama la atención que esta respuesta se produce cuando se pregunta por el tipo de paciente y no por la calidad del profesional.

Resulta evidente entonces que el proceso de valorización de la especialización de los profesionales de la salud se construye procesualmente articulando procesos migratorios, sentidos asociados al trabajo y razones económicas. 


\section{Reflexiones finales}

A lo largo de esta investigación, hemos intentado comprender la relación entre emblematización urbana y profesionales de la salud en la ciudad media como un relato mítico que transmite representaciones y sentidos asociados que encubren y opacan las relaciones sociales constitutivas del proceso de urbanización. La emblematización urbana que estos actores construyen y practican se produce sobre la base de imágenes como la de próceres y de semidioses locales que se vinculan a procesos histórico-estructurales de la región, donde es generalizado el papel de la ciudad-fortín y los guerreros en ella. En torno a la función social estructural que cumplen los sistemas de creencias en el proceso de urbanización, son los propios actores profesionales de la salud quienes asocian la figura del médico a la del héroe y a lo sagrado cuando describen en qué consiste la particularidad de ser médico o profesional de la salud en la ciudad media. A este respecto, podría inferirse -a partir del análisis antropológico- que al proceso de urbanización le corresponde uno de valorización y especialización que es concomitante con procesos de emblematización urbana.

De igual forma, son también los propios profesionales quienes asocian la figura del "laburante" al ejercicio de la medicina en la metrópolis, cuando referencian las instancias de trabajo ad honorem, la figura del concurrente que espera a que se jubilen médicos de mayor edad o cuando aluden a cuánto menos alcanzarían sus ingresos en las ciudades de mayor tamaño o cuánto más podrían ganar allí, pero que de todas maneras no les alcanzaría para comprar la "tranquilidad de la ciudad chica".

Resulta evidente que la interrelación no se da solo entre ciudad media y metrópolis, sino también entre aquella y ciudades medias mayores, que suelen ser capitales de provincia o centros universitarios tradicionales y reconocidos. Esas ciudades intermedias funcionan como espacialidades segregadas de formación y educación de los especialistas del centro bonaerense, mientras que en la metrópolis esta dinámica se da más entre la capital nacional y el conurbano industrial conformado de varios anillos que la rodean. A este respecto, el análisis ha mostrado que la profesionalización y especialización médica constituye un proceso asociado a la urbanización de las ciudades de esta región. Tal proceso se halla atravesado por experiencias migratorias, que los actores narran como períodos de formación asociados al afianzamiento de la carrera y constitución de la familia. En los esquemas imaginarios de los médicos especialistas nativos y residentes de la ciudad estudiada, parecería que las ciudades grandes "son para estudiar" y la ciudad media "para instalar el consultorio y armar la familia", la clínica, la experiencia en el consultorio, etc. Esta "traducción" de la experiencia migratoria en una experiencia de "profesionalización" consigue valorizar el estatus de estos actores en sus relaciones de proximidad, ya que son vecinos respetables que gozan de gran prestigio.

El proceso de emblematización estudiado a partir del desplazamiento y la profesionalización de actores señala que es posible considerar al metropolismo como sistema de valores, y a la migración como un proceso social y un fenómeno sociocultural que produce y reproduce el reconocimiento y la distinción de las capas profesionales y administrativas de la ciudad media. 
La articulación dialéctica entre procesos sociales estructurales, espaciales e institucionales y los imaginarios puestos en juego podría responder a un modo deshistorizador y no procesual de concebir lo social, que está en la base de las concepciones y racionalidades hegemónicas. Esta "deshistorización" parece encarnarse en el sistema sanitario en un reduccionismo de tipo culturalista que enviste a los profesionales de prestigio en el medio local, lo que opaca el proceso migratorio que comparte con otros sectores de la estructura social y los distingue de ellos.

La deshistorizacion se relaciona con el metropolismo, en tanto construye a ciertas regiones como "subdesarrolladas" y a otras como "centrales". Se muestra de forma clara, luego del análisis desarrollado, que el obstáculo del metropolismo local enviste al proceso social de producción de especialistas profesionales con el error empirista -tal como lo entiende Bachelard (2000) en términos epistemológicos- de la capacidad individual. Como quien se fue, estudió y volvió fue uno de los miembros de la comunidad, se naturaliza que es mérito del uno el esfuerzo del todo. Se produce así la narrativa personal de la movilidad de clase por mérito propio, opacando el proceso de valorización social local y de proximidad que permite que esos laburantes metropolitanos adquieran un valor de cambio atractivo en la ciudad media como "eminencias" o profesionales más que como "laburantes" o fuerza de trabajo.

La identificación de este obstáculo ha contribuido por tanto no solo metodológicamente al estudio de los imaginarios urbanos sanitarios locales, sino que ha permitido una apertura analítica a la consideración del metropolismo dentro del fenómeno estudiado. Se pudo corroborar que este forma parte de la emblematización de capas profesionales que a su vez emblematizan la ciudad como la capital regional de la salud. Esa emblematización urbana se evidencia no solo como un sistema de valores que los actores ostentan para distinguirse, sino también como un proceso que ellos mismos experimentan a través del traslado de unas ciudades a otras. Concebimos, en consecuencia, a la metrópolis como un obstáculo epistemológico que requiere de un proceso analítico de reflexividad y extrañamiento en las investigaciones de la ciudad media, que toman por hipótesis de trabajo el metropolismo. En este sentido, el metropolismo puede decirse que resultó en esta investigación, una herramienta heurística que permitió identificar un obstáculo epistemológico.

Dentro de la matriz histórica de la ciudad con las vivencias referenciadas aquí, donde se ponen de relieve las determinaciones históricas y sociales del modo en que los actores viven el espacio urbano, el proceso migratorio que requiere la profesionalización en la ciudad media no suele reconocerse como migración por los actores, porque está asociada a lo que tienen que hacer los "pobres" como grupo para sobrevivir. En cambio, el proceso migratorio de la profesionalización se impregna nativamente de voluntad, elección, esfuerzo, capacidad y éxito individual. Con estos valores y tópicos se construyen las prácticas cotidianas de los profesionales de la ciudad media.

En síntesis, las concepciones nativas de la ciudad media en términos de emblematización constituyen construcciones relacionales y ahistóricas que esencializan características míticamente reproducidas. Es lo 
que hacen los actores al referenciar su mágica transformación de "laburantes" de la gran ciudad metropolitana e intranquila a próceres o semidioses de la apacible "ciudad del trabajo" local. La emblematización funcionaría, por tanto, como un sistema de valores que organiza lo sagrado y lo profano, lo atrasado y lo moderno, lo vivo y lo muerto en las distinciones que provee en torno a "lo que es pueblo" (la ciudad media) y "lo que es una ciudad de verdad" (la metrópolis).

No obstante, nuestro análisis caería en el "ahistoricismo" que criticamos si no asociáramos el metropolismo con el proceso social de producción de valor inherente a la urbanización capitalista. Esta producción de valor concierne especialmente a la gestión municipal de consumos colectivos sanitarios. Un elemento importante de esa gestión es la del hospital público moderno y con tecnología de avanzada (con mucho valor agregado). Los profesionales intervienen en esa dinámica como mediadores y facilitadores de la modernidad que llega al usuario del servicio sanitario, identificándose metonímicamente incluso con sus medios de producción, en este caso los aparatos médicos (cuando por ejemplo señalan "el intendente me compró el resonador"). El proceso de producción de valor se hace presente también en las decisiones "económicas" que toman los profesionales con respecto a dónde desarrollar su actividad profesional, vivir y formar una familia. La "tranquilidad" de la ciudad media vela en este sentido su más provechoso carácter remunerativo -formal e informal- en relación con la costosa metrópolis, donde se sienten apenas un trabajador más. En cambio, en la ciudad media, su trabajo se valoriza más, pues se siente "un prócer", un "semidios", donde lo "tratan distinto", si hasta se fijan de "no meterte los cuernos". La lealtad del paciente en un mercado competititvo, donde, como vimos, la oferta de profesionales aumenta a un ritmo mayor que la de pacientes, parece ser un elemento tan subestimado como importante de la valorización profesional en la ciudad media.

Quizás sea la competencia, en tanto relación capitalista, la que consiga hacer efectiva la emblematización de la ciudad media como capital de la salud y contribuya a obstaculizar una identidad que objetive como "laburantes" o trabajadores (de la "ciudad del trabajo) a los "profesionales de la salud".

\section{Referencias bibliográficas}

Arizpe, L. (1985). Migración, etnicismo y cambio económico. México D.F.: El Colegio de México.

Bachelard, G. (2000). La formación del espíritu científico. Contribución a un psicoanálisis del conocimiento objetivo (23 ${ }^{\text {a }}$ ed.). México D.F.: Siglo XXI.

Balán, J. (1982). Migraciones en el desarrollo capitalista brasileño: ensayo de interpretación histórica comparativa. En O. Argüello, J. Balán, J. Brandao, W. Pencht, V. Faría y C. Stern (eds), Migración y desarrollo 3. Análisis históricos y aspectos relacionados a la estructura agraria y al proceso de urbanización (pp. 65-104). Buenos Aires: CLACSO.

Boggi, S. (2005). “... es la ciudá que ronca”. Olavarría: de fabril a “tuerca”. En A. Gravano (comp.), Imaginarios sociales de la ciudad media: emblemas, fragmentaciones y otredades urbanas, estudios de Antropología Urbana (pp. 41-55). Tandil: Universidad Nacional del Centro de la Provincia de Buenos Aires. 
Boggi, S. y Galván, N. (2016). Ciudad media, ciudad intermedia: ¿ni chicha ni limonada?. En A. Gravano, A. Silva y S. Boggi (eds), Ciudades vividas: sistemas e imaginarios de ciudades medias bonaerenses (pp. 25-48). Buenos Aires: Editorial Café de las Ciudades.

Bourdieu, P. (1979). La distinction: critique sociales du jugement. Paris: Les Editions de Minuit.

Bourdieu, P., Chamboredon, J. C. y Passeron, J. C. (2002). El oficio del sociólogo. Buenos Aires: Siglo XXI Editores.

Bourdieu, P. (2007). El sentido práctico. Buenos Aires: Siglo XX Editores.

Conrad, P. (1982). Sobre la medicalización de la anormalidad y el control social. En D. Ingleby (ed.), Psiquiatría crítica. La política de la salud mental (pp. 129-154). Barcelona: Editorial Crítica.

Conrad, P. y Schneider, J. (1990). Professionalization, monopoly and the structure of medical practice. En P. Conrad and R. Kern (eds), The Sociology of health and illness, critical perspectives (pp. Xx-Xx). New York: St Martin Press.

Castells, M. (1974). La cuestión urbana. Madrid: Siglo XXI.

Childe, G. (1973). Los orígenes de la civilización. México D.F.: Fondo de Cultura Económica.

El Popular. (7 de agosto de 2013). Hubo dos ofertas para el segundo tomógrafo computado del hospital. Diario El Popular. Recuperado de http://www.elpopular.com.ar/eimpresa/167455/hubo-dos-ofertaspara-el-segundo-tomografo-computado-del-hospital

El Popular. (16 de marzo de 2014). El hospital incorpora un segundo tomógrafo. Diario El Popular. Recuperado de http://www.elpopular.com.ar/eimpresa/183363/el-hospital-incorpora-un-segundo-tomografo

Friedson, E. (1978). La profesión médica. Barcelona: Península.

Galarza, B. y Gravano, A. (2012). Salud mental y sistema urbano en una localidad de rango medio. Avá, 21, 171-194.

Galarza, B. (2015). Segregación y dispersión en la atención del derecho a la salud mental en el centro de la provincia de Buenos Aires. Intersecciones en antropología, 16(1), pp. 69-83.

Gluckman, M. (1940). Analysis of a social situation in modern Zululand. Bantu Studies, 14(1), 1-30.

Gravano, A. (2005). Palimpsesto urbano: sobre-escritura de huellas diacrónicas de la ciudad imaginada. En Ariel Gravano (comp.), Imaginarios sociales de la ciudad media: emblemas, fragmentaciones y otredades urbanas. Estudios de Antropología Urbana (pp. 35-49). Tandil: Universidad Nacional del Centro de la Provincia de Buenos Aires.

Gravano, A. (2016). Tres hipótesis sobre la relación entre sistema urbano e imaginarios de ciudades medias.

En A. Silva, S. Boggi y A. Gravano (eds), Ciudades vividas: sistemas e imaginarios de ciudades medias bonaerenses (pp. 69-90). Buenos Aires: Café de las ciudades.

Guber, R. (2009). El salvaje metropolitano. Buenos Aires: Paidós.

Hammersley, M. y Atkinson, P. (1994). Etnografía, métodos de investigación. México D.F.: Paidós.

Harvey, D. (2007). Breve historia del neoliberalismo. Madrid: Akal.

Kapferer, J. N. (1989). Rumores, el medio de difusión más antiguo del mundo. Buenos Aires: Emecé.

Leiro, C. (2005). Esto no es una ciudad..., la meta-imagen mediática como referente. En A. Gravano (comp.), Imaginarios sociales de la ciudad media: emblemas, fragmentaciones y otredades urbanas. Estudios de Antropología Urbana (pp. 69-77). Tandil: Universidad Nacional del Centro de la Provincia de Buenos Aires.

Cuadernos de Antropología 2016, 26(2), 27-50 / ISNN 2215-356X

http://revistas.ucr.ac.cr/index.php/antropologia 
B. Galarza

Lomnitz, L. (1975). Cómo sobreviven los marginados. México D.F.: Siglo XXI.

Mandrini, R. (1988). La sociedad indígena de las Pampas en el siglo XIX. En M. Lischetti (comp.), Antropología (pp. 205-230). Buenos Aires: EUdeBA.

Mitchell, C. (1999). Orientaciones teóricas de los estudios en África. En M. Banton (coord.), Antropología social de las sociedades complejas (pp. 53-81). Madrid: Alianza Editorial.

Mumford, L. (1979). La ciudad en la historia. Buenos Aires: Editorial Infinito.

Municipalidad de Olavarría. (1968). Libro de oro del centenario de Olavarría 1867-1967. Olavarría: Ediciones Aniversario.

Municipalidad de Olavarría. (2007). La salud de nuestros vecinos 1991-2007. Municipalidad de Olavarría: Olavarría.

Silva, A. y Boggi, S. (2016). Estudios sobre imaginarios de ciudades medias. En A. Silva, S. Boggi y A. Gravano (eds), Ciudades vividas: sistemas e imaginarios de ciudades medias bonaerenses (pp. 4968). Buenos Aires: Café de las ciudades.

Singer, P. (1975). Economía política de la urbanización. México D.F.: Editorial Siglo XXI.

Sosa, R. (2016). La educación que necesita la ciudad reconvertida. En A. Silva, S. Boggi y A. Gravano (eds), Ciudades vividas: sistemas e imaginarios de ciudades medias bonaerenses (pp. 237-250). Buenos Aires: Café de las ciudades.

Topalov, C. (1979). La urbanización capitalista. México D.F.: Edicol.

Weber, M. (1979). Economía y sociedad. México D.F.: Fondo de Cultura Económica. 